\title{
Non-idiopathic Clubfeet: A Current Concepts Review
}

\author{
Rujuta Mehta ${ }^{1}$, Nirmal Raj Gopinathan ${ }^{2}$, Karthick Rangasamy ${ }^{3}$
}

\begin{abstract}
The primary goal in managing non-idiopathic clubfeet is to attain a painless and plantigrade foot with as least number of procedures as possible. Preferably, it should be achieved before the walking age to prevent the adaptive changes in the bone. Serial casting by the Ponseti technique is gaining favor for primary management of these feet with encouraging initial correction results. However, recurrence of variable degree is expected. Certain modifications to the treatment are advisable in view of the non-pliability of these feet and high recurrence rates. Manipulation and plastering techniques similar to atypical feet maneuvers need to be practiced very often. Some rigid cases also need an early Achilles tenotomy or limited posterior soft tissue release (STR). The final goal is achieving brace-able plantigrade feet, but in view of the rigidity, an endpoint of abduction correction to $30-40^{\circ}$ with $5-10^{\circ}$ of dorsiflexion is acceptable. Ankle foot orthosis (AFO) in cases with concurrent hip and knee contractures is preferred over standard foot abduction braces (FAB). Recent literature showed that the number of non-idiopathic clubfeet undergoing extensive STR or radical bony procedures has drastically reduced over the years. The jury is still out about consensus on the ideal protocol.
\end{abstract}

Keywords: Arthrogryposis, Clubfoot, Congenital talipes equinovarus, Myelomeningocele, Non-idiopathic, Ponseti, Spina bifida, Syndromic clubfeet.

Journal of Foot and Ankle Surgery (Asia Pacific) (2021): 10.5005/jp-journals-10040-1170

\section{InTRODUCTION}

A large majority of clubfeet presenting to the pediatric outpatient clinic of about $80 \%$ do not have any associated conditions and are termed idiopathic clubfeet. The rest are of a non-idiopathic variety and are secondary to an underlying disorder of the systemic or peripheral neuromuscular apparatus. ${ }^{1,2}$ They intrinsically differ in muscle length, excursion, and pathoanatomy and are essentially rigid. Some authors also describe them as "treatment-resistant clubfeet" or challenging clubfeet since they behave similar to the complex idiopathic clubfeet. Often, similar modifications to treatment are used as corollaries. ${ }^{3-5}$

Conservative outpatient clinic-based treatment using the Ponseti technique has met with resounding universal success and acceptance. Literature is replete with studies on every aspect of successful idiopathic congenital talipes equinovarus (CTEV) management. But the evidence on the management of nonidiopathic variety is limited and evolving.

Previously, syndromic feet were considered resistant to correction by casting; hence, primary extensive soft tissue release (STR) or radical ablative bony procedures like arthrodesis or talectomy were recommended. ${ }^{6,7}$ Recurrences, despite radical approaches, were more the norm than the exception, and hence the results were not gratifying. Corrected feet were stiff and painful at the final long-term follow-up. Recent literature shows promise in early management by the Ponseti method of casting for initial correction, even though the recurrence rates are higher when compared to idiopathic ones. ${ }^{8-11}$

This review aims to analyze and consolidate the current literature trends for etiology, treatment options, outcome measures, and complication rates concerning non-idiopathic clubfeet.

\section{Incidence And Prevalence}

The overall prevalence of clubfoot varies from 1.1 to 1.6 per 1,000 live births. ${ }^{9}$ A significant volume of clubfeet presenting to pediatric
${ }^{1}$ Paediatric Orthopaedic Division, BJ Wadia Hospital for Children, Mumbai, Maharashtra, India; Consultant Paediatric Orthopaedics, Nanavati, Jaslok and Surya Hospitals, Mumbai, Maharashtra, India

${ }^{2,3}$ Department of Orthopaedics, Postgraduate Institute of Medical Education and Research, Chandigarh, India

Corresponding Author: Karthick Rangasamy, Department of Orthopaedics, Postgraduate Institute of Medical Education and Research, Chandigarh, India, Phone: +91 9592094536, e-mail: drsrk05@gmail.com

How to cite this article: Mehta R, Gopinathan NR, Rangasamy K. Nonidiopathic Clubfeet: A Current Concepts Review. J Foot Ankle Surg (Asia Pacific) 2021;8(3):110-117.

Source of support: Nil

Conflict of interest: None

orthopedic clinics about $20 \%$ have associated anomalies. ${ }^{1,2}$ Among these, the most common associated disorders are arthrogryposis and spina bifida. ${ }^{8,9}$ They form a significant chunk of the clubfoot cases managed in clinics. In a recent large single-center study, it was found that non-idiopathic clubfeet comprised $11.38 \%$ of the total cohort of clubfoot cases involved in their research. ${ }^{10}$

\section{Etiopathology}

Arthrogryposis and spina bifida are known to be the commonest etiologies of non-idiopathic clubfeet. Arthrogryposis is a heterogeneous group of many syndromes which have a major clubfoot component as well. Among the other varieties, nonidiopathic clubfeet can be classified into two types-one associated with disorders of soft tissue laxities (Fig. 1) and another group with exceptionally tight soft tissues (rigid type) (Fig. 2). Apart from these, there are bony etiologies like tibial and fibular hemimelia concomitant with clubfoot. The various etiologies are grouped accordingly in Table 1. 

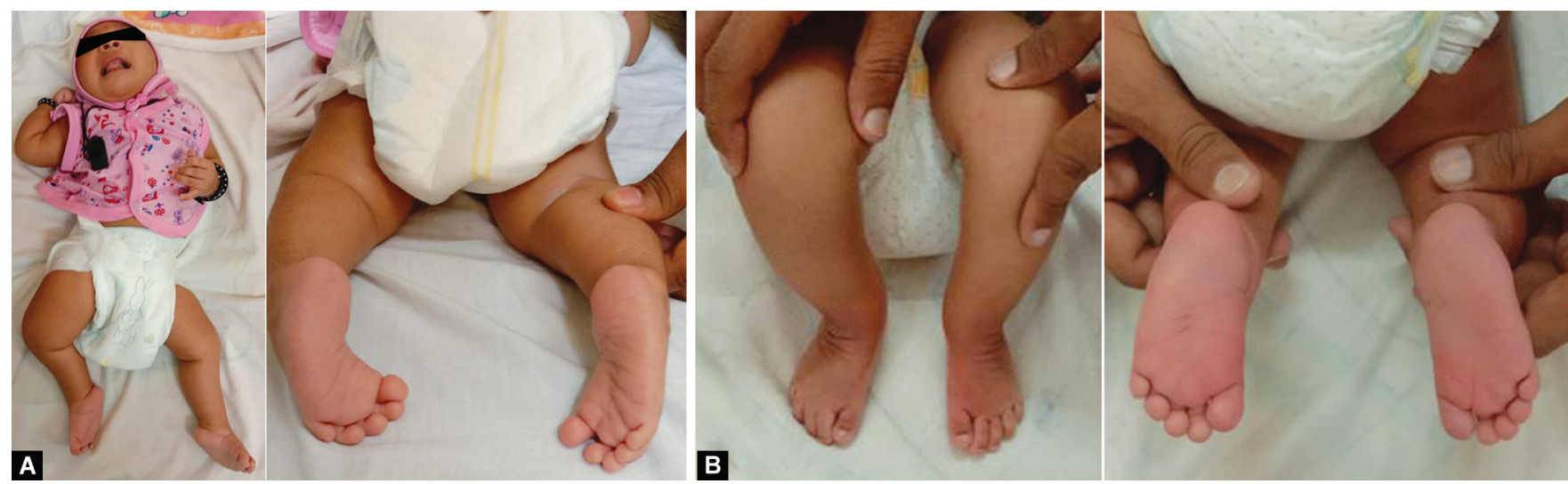

Figs $1 \mathrm{~A}$ and B: (A) Syndromic child having clubfeet with hypotonia; (B) Clubfeet correction achieved by Ponseti method of casting

\section{Neurogenic Clubfoot}

The most typical foot deformity to occur in spina bifida patients is clubfoot which is seen in about 30 to $50 \%$ of those children. ${ }^{12,13}$ It is seen most frequently in lumbar lesions at L3-L4 level and beyond. Sharrard ${ }^{14}$ stated that the most severe manifestations occur from lesions at the L4 level and spasticity (reflex activity) of sacral levels below, resulting mainly in a very rigid equinus. The level of spinal involvement affects the functional motor level and ambulatory capacity. The deformity is usually severe and resistant to treatment and the rate of relapse/recurrence, regardless of treatment, is high. ${ }^{11,15}$ The insensate skin makes these cases more prone to skin breakdown, ulcerations and poses problems with braces and footwear. Treatment aims to make the foot plantigrade brace-able for weight-bearing in both walkers and non-walkers for optimal wheelchair sitting.

Flynn et al. ${ }^{16}$ showed that almost $40 \%$ of children born with myelomeningocele (MMC) have clubfeet, and the rate of poor clinical outcomes is noted highest when the MMC is present at the thoracic level. These feet are very rigid, insensate, and more severely deformed. van Bosse ${ }^{17}$ had highlighted the need for modification to Ponseti protocol due to the spasticity of triceps surae in MMC children by performing a limited open Achilles tendon tenotomy (ATT) at the outset to tackle the rigid equinus, which otherwise poses a roadblock to successful correction.

\section{Clubfeet Associated with Arthrogryposis Multiplex Congenita (AMC)}

Although this variety spans across almost 400 subtypes of disorders, the primary pathology is common. Hall and colleagues ${ }^{18,19}$ studied it extensively, and fundamental research is still on. Congenital talipes equinovarus is considered a primary connective tissue abnormality because of the evidence of retractile fibrosis along with the shortening of ligaments and tendons in histopathology. However, these findings could also be seen secondarily following neuromuscular unit abnormalities. Mutations in embryonic myosin heavy chain are found to occur in distal arthrogryposis (DA) syndromes. Contractures are believed to be caused by brief periods of embryonic akinesia.

Moon et al. ${ }^{20}$ demonstrated a more significant proportion of soft-tissue abnormalities in the treatment-resistant clubfoot patients group. They are excessive epimysial fat, intracompartmental and intramuscular replacement with fat, and hypoplasia with characteristic patterns in the specific muscle groups, compared with patients of treatment-responsive clubfoot and unilateral non affected foot in the syndromic child. These findings demonstrated decreased suppleness and reduced ability to maintain correction, no surprise then to relatively poor correction rates and provided a solid basis to a higher relapse.

\section{Genetics}

Recent literature on the molecular basis has proven that the non-idiopathic clubfoot results from structural deformities of various tissues in the foot and those in the lower leg. ${ }^{21}$ It has been demonstrated consistently that the muscle contractile genes play a crucial role in DA. Sadler et al. ${ }^{21}$ categorized the genes associated with syndromic clubfoot into those involved in transforming growth factor-beta (TGF- $\beta$ ) signaling causing paroxysmal defects in components of extracellular matrix, and proteoglycans. Also, the authors were able to demonstrate that specific genes like Filamin B (FLNB) are linked with isolated clubfoot and autosomal dominant Larsen syndrome.

Congenital myopathies associated with DA, amyoplasia congenita have led to many in vitro studies. Electron microscopy studies have identified in stillborn fetal specimens a mutation leading to excess contractile function in the skeletal muscle fasttwitch fiber regulatory proteins, namely troponin I, troponin $T$, and beta-tropomyosin. 22

These studies indicate a vast scope for research into the genetic aspects of treatment-resistant clubfeet. This broad term encompasses several types of non-idiopathic clubfeet. It opens up further avenues for further interest and future research, which may change how these resistant feet are perceived and dealt with.

\section{Evaluation}

Evaluation of children with non-idiopathic clubfeet should be done by a pediatric neurologist, neonatologist, and geneticist besides the pediatric orthopedist. A cervical spine radiograph is mandatory in cases of Down and Larsen syndrome to look for spinal instability before any surgical intervention. In an insensate foot, look for skin ulceration and breakdown. In older children, radiographic evaluation of foot is sparingly used for cases that are not amenable to serial plastering.

No single scoring system has been validated for syndromic clubfeet. The Pirani score was developed for idiopathic clubfoot in neonates, both for gauging severity and an outcome measure. Boehm et al. ${ }^{23}$ and some other authors have preferred the Dimeglio score since it also takes into account four additional points that define the soft tissue contractures in addition to the 16 points that measure reducibility and movements. Niki's criteria ${ }^{24,25}$ have been 


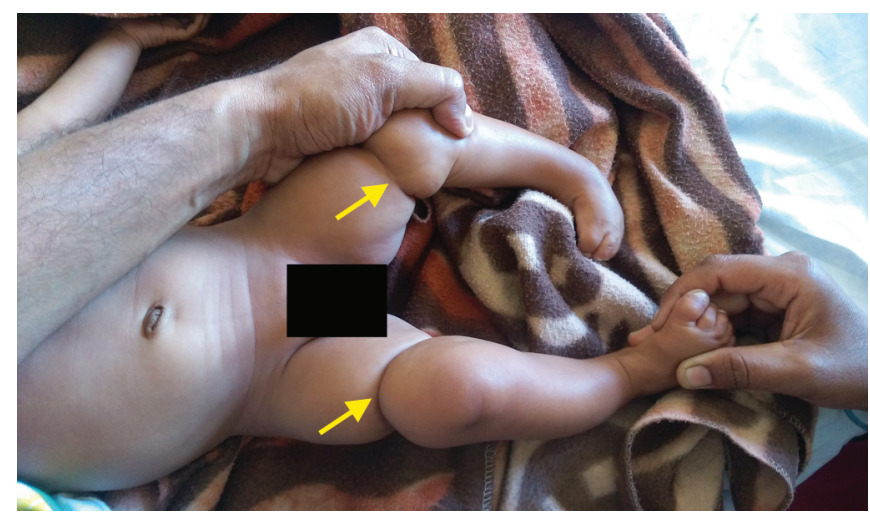

Fig. 2: Streeter's dysplasia child having constriction rings with rigid type-clubfeet

Table 1: Classification of non-idiopathic clubfeet based on structural rigidity

\begin{tabular}{ll}
\hline Disorders with soft tissue rigidity & Disorders with soft tissue laxity \\
\hline Arthrogryposis (AMC) & Larsen's syndrome \\
Neurogenic (spina bifida) & Down's syndrome \\
Streeter's dysplasia & Flail MMC's \\
Freeman Sheldon syndrome & Congenital deletion syndromes \\
Diastrophic dysplasia & Congenital hypotonic myopathies \\
Mobius syndrome & Hemimelias* \\
Prune belly syndrome & \\
Tibial Hemimelia &
\end{tabular}

${ }^{*}$ Clubfoot associated with hemimelias present mostly as a rigid variety but in some cases with soft tissue laxity also

quoted more as an outcome measure, but these are highly variable and subjective. Newer scoring systems are being discussed for the walking age clubfoot in recent literature again, about idiopathic clubfeet, which have undergone secondary changes. No single score applies to all clinical aspects in all varieties etiologies of non-idiopathic clubfeet, and the jury is still out about the most satisfactory and suitable scoring system. Until that is developed, the Dimeglio scoring should be a reasonable fallback both for clinical treatment parameters and a research tool.

\section{Treatment and Outcomes}

Compared to idiopathic clubfoot, the treatment of non-idiopathic clubfeet is complex and challenging, and hence families should be counseled at the very outset regarding the same. Given that the paradigm is shifting towards initial early casting, the whole of the surgical indications, armamentarium, methodology, and outcomes should be known to the experienced pediatric orthopedic surgeon.

\section{Surgical Management}

In the past, non-idiopathic clubfeet were classically operated directly with initial extensive tissue releases and ablative soft bony surgeries like talectomy, the rigidity being the primary indication, especially in arthrogryposis. Talectomy, in recent years, has fallen out of vogue due to poor long-term outcomes of secondary ankle arthritis and hence is no longer recommended as a primary procedure. It may still be advocated for secondary relapses. Bony osteotomies and distraction techniques followed by open procedures are still recommended and popular, especially in the older syndromic child at many centers. Initial casting even in the most severe pathologies as a prelude to definitive surgery is well accepted as a means of reducing the requirements of extensive releases.

Widmann et al., ${ }^{26}$ in their mean follow-up of 4.3 years, noted good outcomes in $50 \%$ of arthrogrypotic clubfeet children under 1 year of age who underwent radical STR. All the six patients (12 feet) in their group had a mean of 7 casts preoperatively. In addition to releases on the posteromedial aspect, they also performed an extensive resection of tendons on the extensor and lateral aspect along with the use of a Steinman pin. They retained it for a long time to maintain the correction. Similarly, Flynn et al., ${ }^{16}$ de Carvalho Neto et al., ${ }^{13}$ and Hennigan and $\mathrm{Kuo}^{27}$ had shown variable results with $61-63 \%$ success rates in syndromic children mainly with spina bifida and constriction bands treated with surgical management. Historically in 1971, Menelaus ${ }^{6}$ first recommended the practice of talectomy to correct hindfoot varus and ankle equinus deformity in cases of non-idiopathic clubfeet. In 1978, Drummond and Cruess, ${ }^{7}$ after reviewing the management of arthrogrypotic foot deformity had concluded that talectomy was considered to be the highly successful surgical technique in their study series, which was later supported by few other studies. ${ }^{28}$ Recent studies have raised questions regarding the long-term effects following talectomy, and Legaspi et al. ${ }^{29}$ showed good results in only $33 \%$ of cases, fair in $42 \%$, and poor outcomes in $25 \%$ of cases at a follow-up period of 20 years.

The literature concerning specific pathologies and different stages of management is summarized as follows.

\section{Arthrogryposis Multiplex Congenita}

Morcuende et al. ${ }^{30}$ first published the report on the Ponseti method in which 16 patients with bilateral arthrogrypotic clubfeet were treated. $67.75 \%$ of cases showed satisfactory outcomes during an average follow-up period of 4.6 years. Boehm et al. ${ }^{23}$ showed a $92 \%$ good outcome in the treatment of DA. But $6 / 24$ feet (25\%) had a recurrence, and they were successfully corrected by repeat casting. van Bosse et al. ${ }^{17,31}$ showed promising results in 10 arthrogrypotic patients (19 clubfeet) treated with modified Ponseti method by first performing a percutaneous Achilles tenotomy initially for unlocking the calcaneus from the posterior tibia and calling it an accelerated protocol. They cited the spasticity of the triceps surae as being the main offender to correction by casting and hence started the casting post operative to a primary percutaneous Tendo achillies tenotomy, followed by weekly casts till adequate abduction and dorsiflexion were achieved. A second percutaneous Achilles tenotomy was performed thereafter if required to achieve improved dorsiflexion. Kowalczyk and Lejman ${ }^{25}$ reported a $70 \%$ success rate in their study of 10 arthrogrypotic clubfeet treated with the Ponseti method, and the number of manipulations, casts applied ranged from 7 to 10 (mean 8.4). Percutaneous Achilles tenotomy was done for all children with rigid equinus at an average of 14.4 weeks (8-20 weeks). In 2016, Matar et al. ${ }^{32}$ studied 17 arthrogrypotic clubfeet and found satisfactory outcomes in $2 / 3$ rd patients (64.7\%) at their final follow-up. As arthrogrypotic feet are more rigid when compared to idiopathic, the correction might not be achieved ultimately, and the target is to get about $30-40^{\circ}$ of abduction and $5-10^{\circ}$ dorsiflexion.

\section{Neurogenic}

Dobbs et al. ${ }^{33}$ noted excellent results with the Ponseti method in treating clubfeet related to myelodysplasia. Surgical release was needed for only $6 \%$ of the clubfeet cases in his study series. Gerlach 
et al. ${ }^{34}$ reported an $85.7 \%$ success rate, and in 2017, Matar et al. ${ }^{15}$ showed an $83.3 \%$ success rate with casting by the Ponseti method in clubfeet cases that is associated with myelomeningocele.

De Mulder et al. ${ }^{9}$ compared outcomes between clubfeet that are associated with myelomeningocele and with arthrogryposis, and they found that the first group had a less number of casts (5.4 vs 7.2) and a higher success rate of treatment at their final follow-up ( 81.8 vs $58.2 \%)$. But the complication rates are more in the myelomeningocele group in comparison to arthrogrypotic clubfeet undergoing Ponseti casting. The causes of recurrence are non-compliance or intolerant to bracing protocol, reduced function of evertor muscle and severity of the deformity, and the presence of coexisting deformities.

Some studies combined initial casting and addressed residual deformities with soft tissue surgeries. Kowalczyk and Felus ${ }^{35}$ did the serial casting along with primary STR in cases of non-idiopathic clubfeet and showed a $25.5 \%$ success rate in correction without recurrence. In 2004, Flynn et al. ${ }^{16}$ showed $62.5 \%$ good and $25 \%$ fair results in clubfeet associated with myelomeningocele treated initially by serial manipulation and casting and later by extensive posteromedial soft tissue surgery without any internal fixation. They found that forefoot adduction was the most prevalent residual deformity following surgery. A poor clinical outcome was noted if myelomeningocele was at dorsal spine level. Niki et al., ${ }^{24}$ in their 118 months mean follow-up of non-idiopathic clubfeet managed by initial serial casting and later by primary STR, reported good results in $46.3 \%$ of their cases.

De Mulder et al. ${ }^{9}$ suggested surgery is beneficial and frequently the best option due to advanced bony deformities and additional stiffness in older children with clubfoot. Extensive STRs or talectomy should be reserved for the very severe rigid clubfeet not responding to the Ponseti method of correction.

\section{Role of the Ponseti Method in the Management of Non-idiopathic Clubfoot}

De Mulder et al. ${ }^{9}$ in 2018 did a systematic review on the management of non-idiopathic clubfeet by the Ponseti method. They found that in comparison to idiopathic ones, non-idiopathic variety required a more significant number of casts, had an elevated rate of ATT, more recurrences (43.3 vs $11.5 \%)$, and at final follow-up reduced successful treatment rates (69.3 vs $95.0 \%$ ). They recommended the Ponseti method as the primary treatment modality for correcting non-idiopathic clubfeet belonging to the younger age group.
A recent study ${ }^{10}$ which is one of the largest series on nonidiopathic clubfeet analyzed the outcome of the Ponseti method in the management of non-idiopathic clubfeet (group I, $n=146$ feet) and compared them with idiopathic clubfeet (group II, $n=$ 1,032 feet) in a program-based approach using a standardized protocol. They found that in comparison to group II, the group I needed a significantly more number of casts, less initial correction rates, and also had a more significant rate of ATT (Figs 3 and 4). The recurrence rates were significantly more in group $I$. The recurrence cases in group I are managed mainly by re-casting, with only 9/89 patients required extensive soft tissue surgery or fixators. In their mean follow-up of 5.8 years, they found that the success rate in group I was $87.7 \%$ (Table 2). They suggested that, in syndromic and neuromuscular conditions associated with clubfeet, the Ponseti method is an initial effective treatment option.

Janicki et al. ${ }^{8}$ evaluated the Ponseti method in neuromuscular clubfeet and syndrome-associated (non-idiopathic) clubfeet. They studied 40 clubfeet ( 23 children), and semi-rigid fiberglass material was used for casting. The Ponseti method was found to be successful in $77.5 \%$ of cases of non-idiopathic clubfeet. When non-idiopathic clubfeet were compared with idiopathic clubfeet, non-idiopathic ones needed a higher number of casts. They also had a higher failure rate, more recurrence, and additional procedures than the idiopathic clubfeet. They concluded that although the Ponseti method has a higher success rate in idiopathic clubfeet than non-idiopathic clubfeet, correction is attained and maintained in most of the non-idiopathic clubfeet too. Also, if surgery is required for recurrence in some cases, it is less extensive after Ponseti correction.

Moroney et al. ${ }^{11}$ did a single-center study on evaluating the Ponseti method of correction in 43 cases of non-idiopathic clubfeet prospectively. They found the Ponseti method was successful in $63 \%$, and the recurrence rate was $44 \%$, and $37 \%$ required extensive surgical STR. Dunkley et al. ${ }^{36}$ published outcomes of Ponseti service led by the physiotherapist in managing non-idiopathic clubfoot. They conclude that although non-idiopathic clubfeet needed more casts, they also had a higher failure rate, more recurrences, and additional procedures than idiopathic clubfeet. In $70 \%$ of nonidiopathic cases, major surgical procedures were avoided.

\section{Maintenance of Correction (Bracing)}

Compliance with an orthosis is paramount and often needs to be accommodative to the etiologies and associated features. Unlike idiopathic clubfeet, where we aim for $70^{\circ}$ abduction and $15-20^{\circ}$
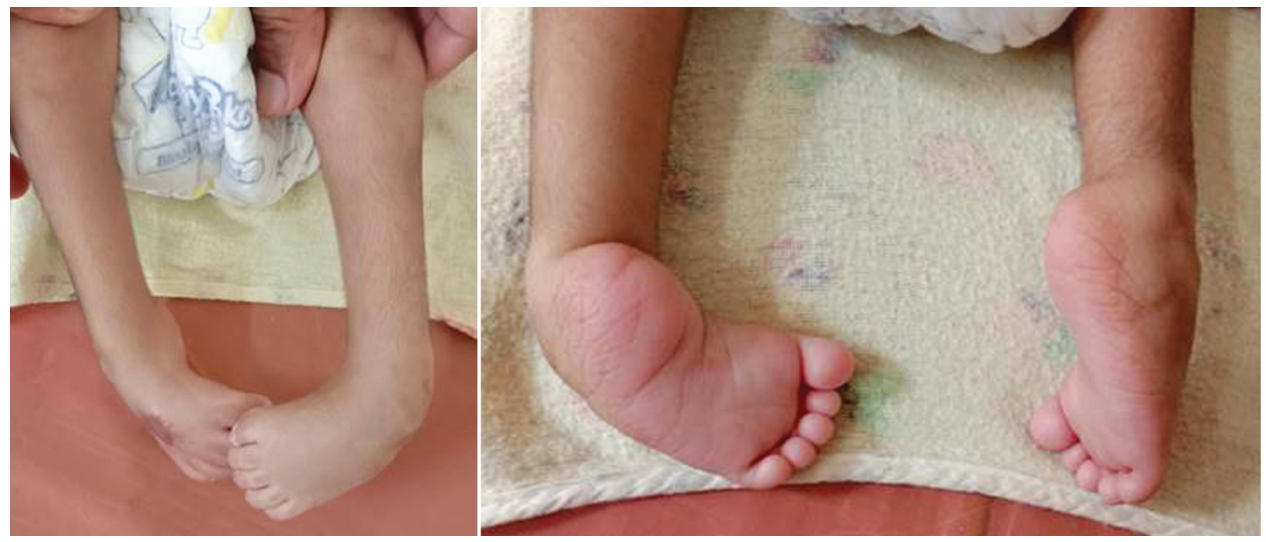

Fig. 3: Child having rigid, non-idiopathic clubfeet 

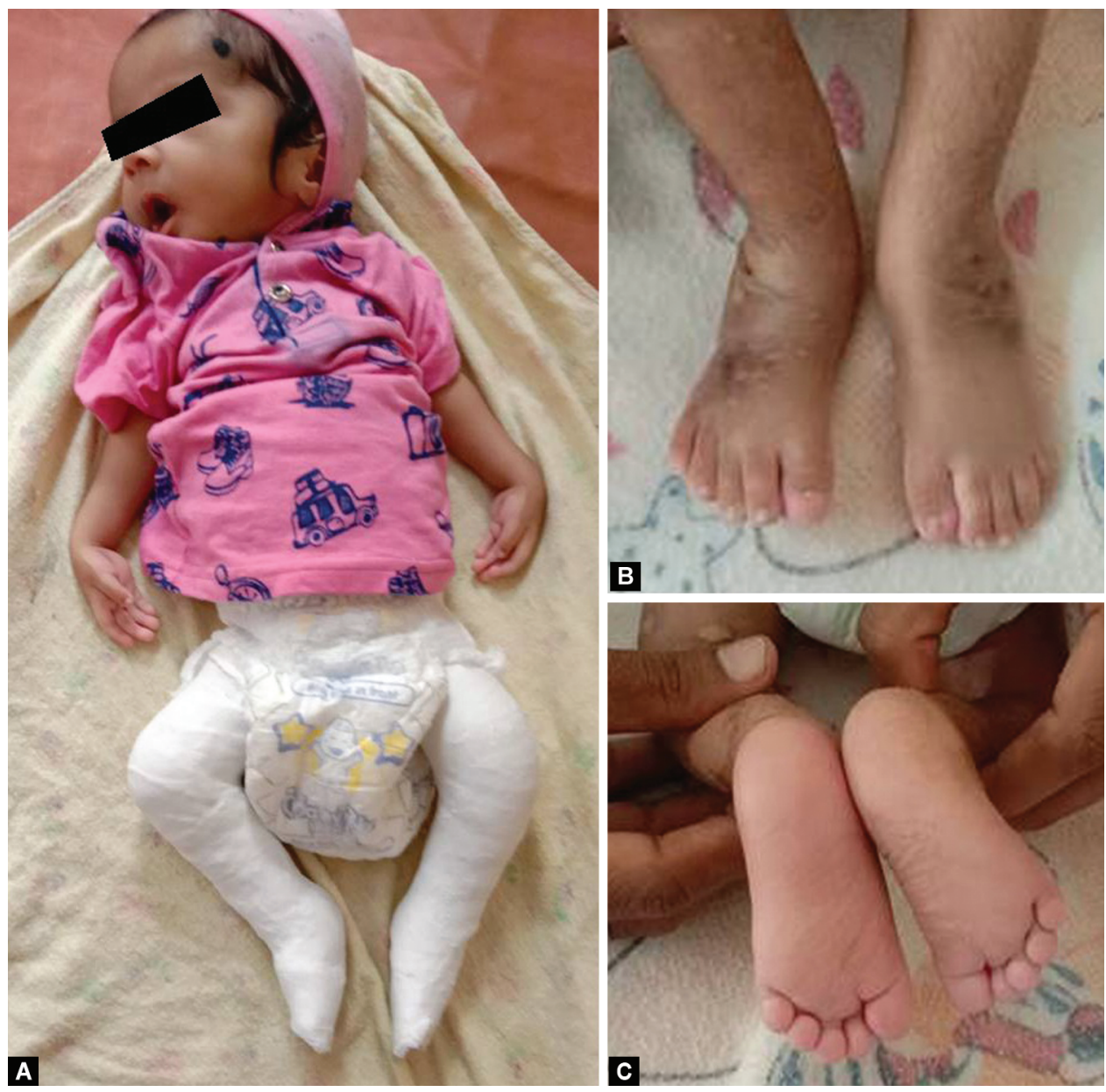

Figs 4A to C: Correction achieved by Ponseti method of casting

Table 2: Comparing different studies on characteristics and outcomes in non- idiopathic clubfeet treated by the Ponseti method

\begin{tabular}{|c|c|c|c|c|c|}
\hline Characteristics & Janicki et al. ${ }^{8}$ (2009) & $\begin{array}{l}\text { Moroney et al. }{ }^{11} \\
\text { (2012) }\end{array}$ & $\begin{array}{l}\text { Dunkley et al. }{ }^{36} \\
\text { (2015) }\end{array}$ & $\begin{array}{l}\text { De Mulder et al. }{ }^{9} \\
\text { (2018) }\end{array}$ & Shah et al. ${ }^{10}(2020)$ \\
\hline Study design & $\begin{array}{l}\text { Retrospective cohort } \\
\text { study }\end{array}$ & $\begin{array}{l}\text { Prospective cohort } \\
\text { study }\end{array}$ & $\begin{array}{l}\text { Prospective cohort } \\
\text { study }\end{array}$ & Systematic review & $\begin{array}{l}\text { Retrospective } \\
\text { cohort study }\end{array}$ \\
\hline Number of feet & 40 & 43 & 69 & 374 & 146 \\
\hline Initial correction (\%) & 90 & 90.7 & 95.7 & 92.1 & 92.5 \\
\hline Mean number of casts & 6.4 & 6.4 & 7 & 7.2 & $6.75 \pm 4.2$ \\
\hline Need for Achilles tenotomy (\%) & 68 & - & 82.6 & 89.4 & 90.4 \\
\hline Successful treatment (\%) & 77.5 & 62.8 & 66.7 & 69.3 & 87.7 \\
\hline Recurrence (\%) & 44.4 & 43.6 & 36.4 & 43.3 & 42.5 \\
\hline
\end{tabular}

dorsiflexion, for the non-idiopathic variety, $30-40^{\circ}$ abduction and $5-10^{\circ}$ dorsiflexion are realistically achievable and suffice. Brace modification is the order of the day for children with knee contractures which are simultaneously treated with the clubfeet. Ankle foot orthosis (AFO) is preferred over foot abduction braces (FAB) in non-idiopathic clubfeet. Care should be taken to ensure good molding, plantigrade alignment, non-irritant inner lining, and soft padding to prevent skin breakdowns.

\section{Management of Recurrence}

The most common complication is the recurrence of deformity (owing to skin ulceration in the insensate foot). The common recurrence being ankle equinus returning along with forefoot adduction. Ulceration prevents bracing in any form, takes a long time to heal, which, if left uncorrected for a long period, causes the contracture to reappear. The most critical factor responsible for clubfoot relapse is non-compliance with braces. A recent study from India ${ }^{10}$ reported a $42.5 \%$ recurrence in non-idiopathic cases vs $10.2 \%$ recurrence in the idiopathic clubfoot group. Most minor recurrences are treated by manipulation and re-casting, and $24 \%$ of patients underwent a repeat Achilles tenotomy. Among 14 feet that failed to respond to re-casting, 4 feet were treated by tendoAchilles lengthening. Only 6 feet required extensive STR, and 4 feet responded to the distraction of soft tissue with a mini external 

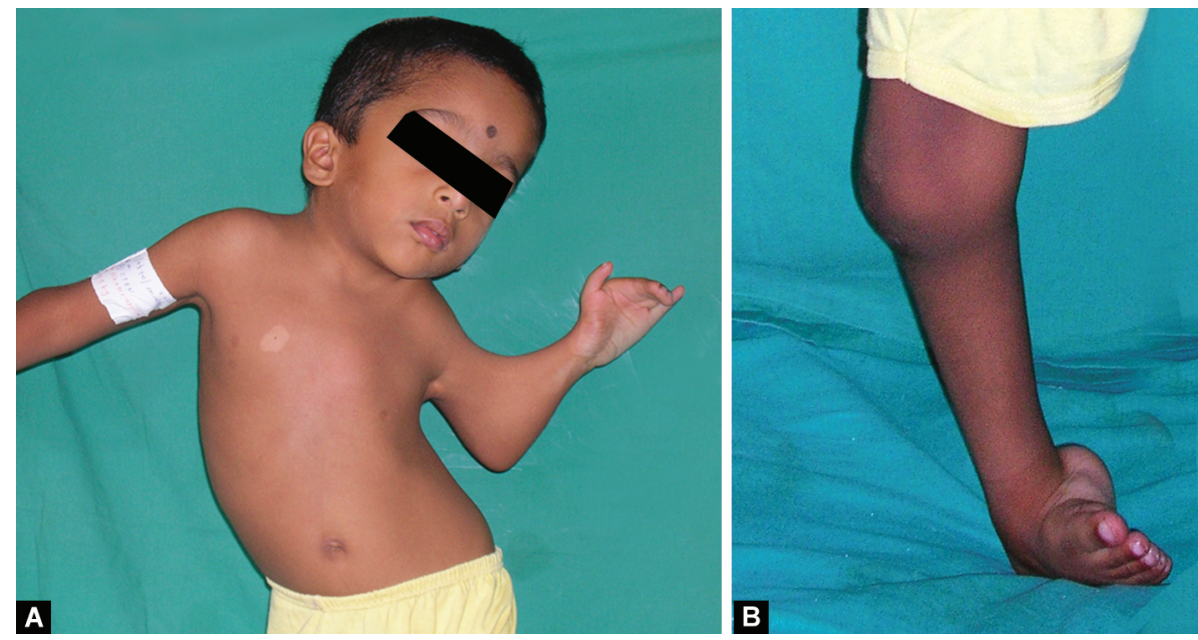

Figs 5 A and B: Syndromic child having facial dysmorphism, elbow pterygium, syndactyly with clubfoot
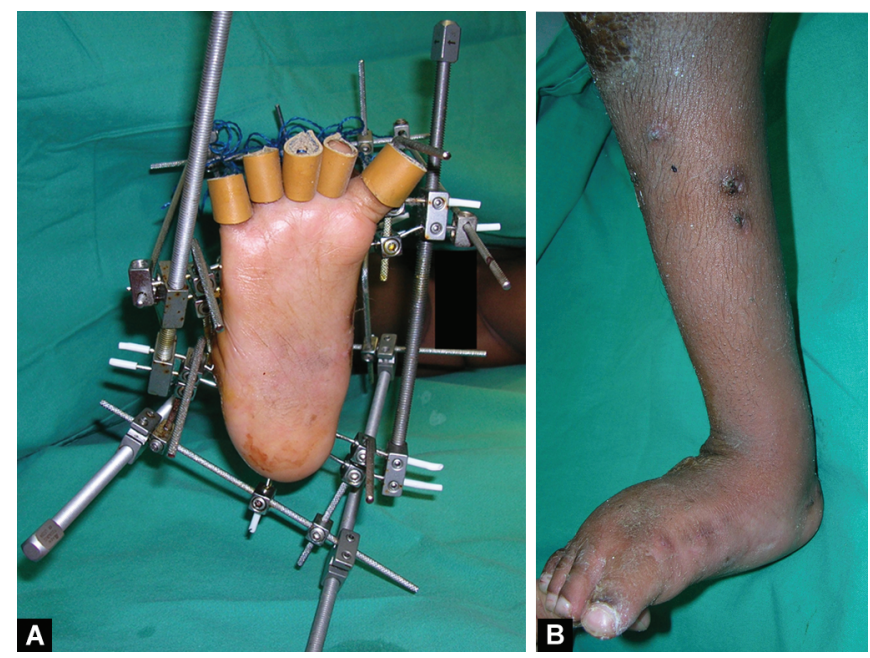

Figs $6 \mathrm{~A}$ and $\mathrm{B}$ : Clubfoot correction achieved by distraction using JESS fixator

fixator. Their results showed that the recurrence cases are managed mainly by re-casting, and $<25 \%$ of recurrences underwent more extensive STR or distraction using an external fixator. No one in their series required osteotomies or talectomies.

\section{Role of Distraction Techniques Using External Fixators}

Another area of interest is using closed distraction techniques combined with or without bony and soft tissue procedures like Joshi External Stabilizing System (JESS)/llizarov apparatus or Taylor's spatial frame, etc. (Figs 5 and 6). Correction by llizarov external fixator ${ }^{37}$ can also be used primarily in older children or in cases of second- or third-time recurrences where there is scar tissue preventing further correction or management.

Initially, the apprehension was that in these severe rigid feet, corrections using llizarov fixator might crush the bony surfaces rather than achieve correction at the joints leading to spurious plantigrade but woody feet. But recent literature has shown benefit in a carefully selected population. Eidelman and Katzman ${ }^{38}$ shared their experience using the Taylor spatial frame (TSF) in arthrogrypotic clubfeet that were operated previously either by
STRs or the llizarov fixator. They showed satisfactory correction by using soft-tissue distraction alone or along with midfoot or supra malleolar osteotomies.

The algorithm for managing non-idiopathic clubfeet is given in Flowchart 1

\section{Conclusion}

- Ponseti's method of correction should be the initial treatment of clubfeet irrespective of etiology.

- Compared to idiopathic clubfeet, the recurrence rates, number of casts, and the requirement of additional surgical procedures are more in non-idiopathic clubfeet.

- Non-compliance with braces is the most critical factor responsible for clubfeet recurrence. An AFO is preferred over FAB.

- Recurrences can be treated by manipulation and re-casting.

- Recent studies showed that the number of cases undergoing extensive STRs or radical bony procedures has drastically reduced.

\section{Authors Contributions}

Rujuta Mehta: Concept and design of work, Content, References, critical revision of the manuscript; Nirmal Raj Gopinathan: Supervision, data collection, and critical revision of the manuscript; Karthick Rangasamy: Drafting-original manuscript, Data acquisition and interpretation; All the authors read the final manuscript and approved it for submission.

\section{References}

1. Wynne-Davies R. Family studies and the cause of congenital club foot. Talipes equinovarus, talipes calcaneo-valgus and metatarsus varus. J Bone Joint Surg [Br] 1964;46-B(3):445-463. DOI: 10.1302/0301620X.46B3.445.

2. Gurnett CA, Boehm S, Connolly A, et al. Impact of congenital talipes equinovarus etiology on treatment outcomes. Dev Med Child Neurol 2008;50(7):498-502. DOI: 10.1111/j.1469-8749.2008.03016.x.

3. Chu A, Nechaime $H$, Lehman WB. Management of the complex clubfoot. JPOSNA 2019;1:1-7. 
Flowchart 1: Algorithm showing how to manage a child with non-idiopathic clubfeet

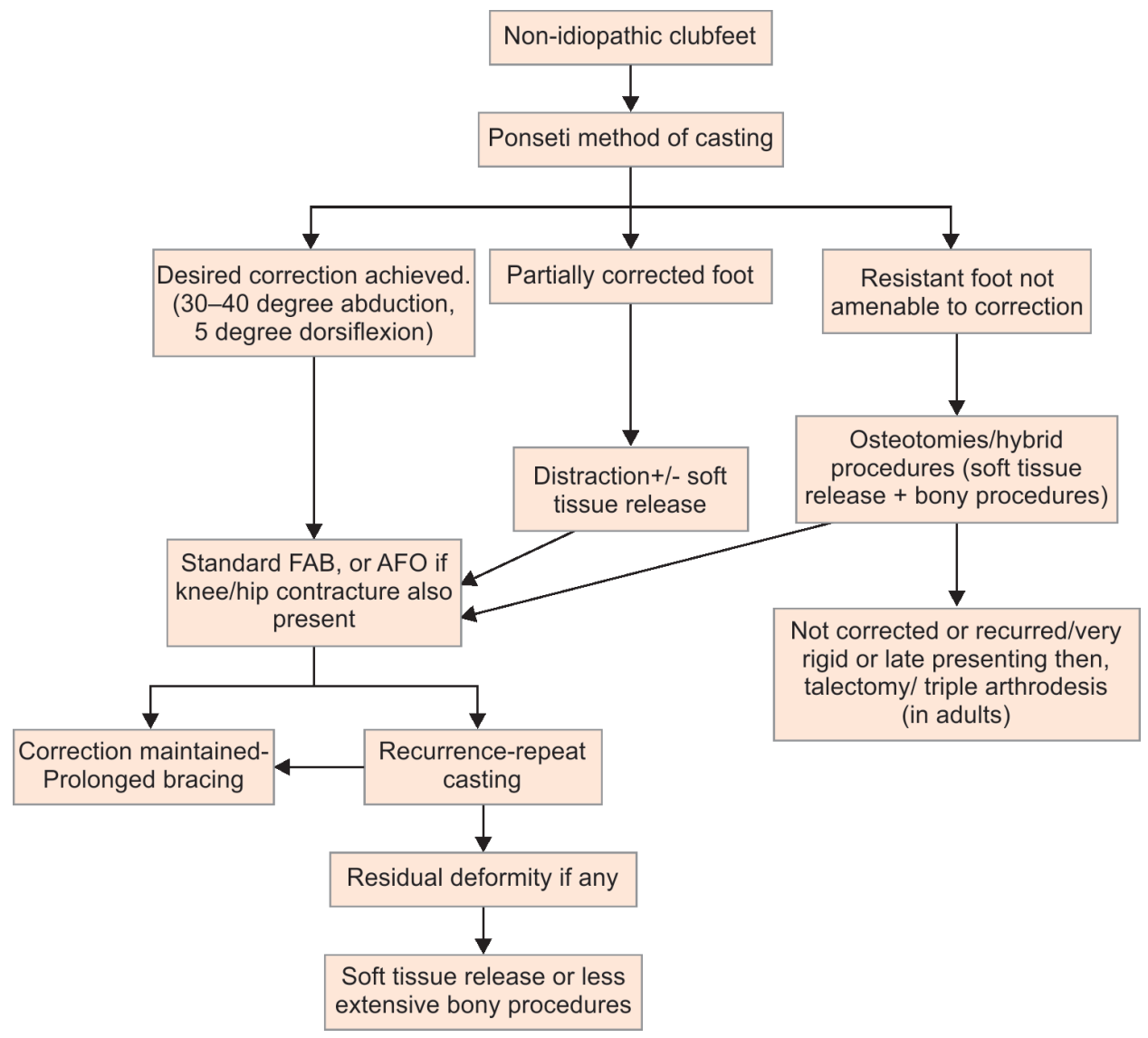

4. van Bosse HJP. Challenging clubfeet: the arthrogrypotic clubfoot and the complex clubfoot. J Child Orthop 2019;13(3):271-281. DOI: 10.1302/1863-2548.13.190072.

5. Ponseti IV, Zhivkov M, Davis N, et al. Treatment of the complex idiopathic clubfoot. Clin Orthop Relat Res 2006 Oct;451:171-176. DOI: 10.1097/01.blo.0000224062.39990.48.

6. Menelaus MB. Talectomy for equinovarus deformity in arthrogryposis and spina bifida. J Bone Joint Surg Br 1971;53-B(3):468-473. DOI: 10.1302/0301-620X.53B3.468.

7. Drummond DS, Cruess RL. The management of the foot and ankle in arthrogryposis multiplex congenita. J Bone Joint Surg $\mathrm{Br}$ 1978;60(1):96-99. DOI: 10.1302/0301-620X.60B1.627587.

8. Janicki JA, Narayanan UG, Harvey B, et al. Treatment of neuromuscular and syndrome-associated (nonidiopathic) clubfeet using the Ponseti method. J Pediatr Orthop 2009;29(4):393-397. DOI: 10.1097/ BPO.0b013e3181a6bf77.

9. De Mulder T, Prinsen S, Van Campenhout A. Treatment of nonidiopathic clubfeet with the Ponseti method: a systematic review. J Child Orthop 2018;12(6):575-581. DOI: 10.1302/1863-2548.12.180066.

10. Shah A, Aroojis A, Mehta R. The Ponseti method of treatment for neuromuscular and syndromic (non-idiopathic) clubfeet: evaluation of a programme-based approach at a mean follow-up of 5.8 years. Int Orthop 2020;45(1):155-163. DOI: 10.1007/s00264-020-04677-9.

11. Moroney PJ, Noël J, Fogarty EE, et al. A single-center prospective evaluation of the Ponseti method in nonidiopathic congenital talipes equinovarus. J Pediatr Orthop 2012;32(6):636-640. DOI: 10.1097/ BPO.0b013e31825fa7df.

12. Akbar M, Bresch B, Seyler TM, et al. Management of orthopaedic sequelae of congenital spinal disorders. J Bone Joint Surg Am 2009;91(Supplement_6):87-100. DOI: 10.2106/JBJS.I.00613.
13. de Carvalho Neto J, Dias LS, Gabrieli AP. Congenital talipes equinovarus in spina bifida: treatment and results. J Pediatr Orthop 1996;16(6):782-785. DOI: 10.1097/01241398-199611000-00015.

14. Sharrard WJ. The orthopaedic surgery of spina bifida. Clin Orthop Relat Res 1973;92(92):195-213. DOI: 10.1097/00003086-19730500000016.

15. Matar HE, Beirne P, Garg NK. Effectiveness of the Ponseti method for treating clubfoot associated with myelomeningocele: $3-9$ years follow-up. J Pediatr Orthop B 2017;26(2):133-136. DOI: 10.1097/ BPB.0000000000000352.

16. Flynn JM, Herrera-Soto JA, Ramirez NF, et al. Clubfoot release in myelodysplasia. J Pediatr Orthop B 2004;13(4):259-262. DOI: 10.1097/01.bpb.0000124491.13918.b7.

17. van Bosse HJ. Syndromic feet: arthrogryposis and myelomeningocele. Foot Ankle Clin 2015;20(4):619-644. DOI: 10.1016/j.fcl.2015. 07.010 .

18. Hall JG. Arthrogryposis (multiple congenital contractures): diagnostic approach to etiology, classification, genetics, and general principles. Eur J Med Genet 2014;57(8):464-472. DOI: 10.1016/j.ejmg.2014.03.008.

19. Hall JG. Arthrogryposis multiplex congenita: etiology, genetics, classification, diagnostic approach, and general aspects. J Pediatr Orthop B 1997;6(3):159-166. DOI: 10.1097/01202412-19970700000002.

20. Moon DK, Gurnett CA, Aferol H, et al. Soft-tissue abnormalities associated with treatment-resistant and treatment-responsive clubfoot: findings of MRI analysis. J Bone Joint Surg Am 2014;96(15):1249-1256. DOI: 10.2106/JBJS.M.01257.

21. Sadler B, Gurnett CA, Dobbs MB. The genetics of isolated and syndromic clubfoot. J Child Orthop 2019;13(3):238-244. DOI: 10.1302/1863-2548.13.190063. 
22. Kowalczyk B, Feluś J. Arthrogryposis: an update on clinical aspects, etiology, and treatment strategies. Arch Med Sci 2016;12(1):10-24. DOI: 10.5114/aoms.2016.57578.

23. Boehm S, Limpaphayom N, Alaee F, et al. Early results of the Ponseti method for the treatment of clubfoot in distal arthrogryposis. J Bone Joint Surg Am 2008;90(7):1501-1507. DOI: 10.2106/JBJS.G. 00563.

24. Niki H, Staheli LT, Mosca VS. Management of clubfoot deformity in amyoplasia. J Pediatr Orthop 1997;17(6):803-807. DOI: 10.1097/01241398-199711000-00020.

25. Kowalczyk B, Lejman T. Short-term experience with Ponseti casting and the Achilles tenotomy method for clubfeet treatment in arthrogryposis multiplex congenita. J Child Orthop 2008;2(5):365371. DOI: 10.1007/s11832-008-0122-0.

26. Widmann RF, Do TT, Burke SW. Radical soft-tissue release of the arthrogrypotic clubfoot. J Pediatr Orthop B 2005;14(2):111-115. DOI: 10.1097/01202412-200503000-00010.

27. Hennigan SP, Kuo KN. Resistant talipes equinovarus associated with congenital constriction band syndrome. J Pediatr Orthop 2000;20(2):240-245. DOI: 10.1097/01241398-20000300000021.

28. Hsu LC, Jaffray D, Leong JC. Talectomy for club foot in arthrogryposis. J Bone Joint Surg Br 1984;66(5):694-696. DOI: 10.1302/0301620X.66B5.6501362.

29. Legaspi J, Li YH, Chow W, et al. Talectomy in patients with recurrent deformity in club foot. A long-term follow-up study. J Bone Joint Surg Br 2001;83-B(3):384-387. DOI: 10.1302/0301-620x.83b3.11051.

30. Morcuende JA, Dobbs MB, Frick SL. Results of the Ponseti method in patients with clubfoot associated with arthrogryposis. lowa Orthop J 2008:28:22-26.
31. van Bosse HJ, Marangoz S, Lehman WB, et al. Correction of arthrogrypotic clubfoot with a modified Ponseti technique. Clin Orthop Relat Res 2009;467(5):1283-1293. DOI: 10.1007/s11999-0080685-6.

32. Matar HE, Beirne P, Garg N. The effectiveness of the Ponseti method for treating clubfoot associated with arthrogryposis: up to 8 years follow-up. J Child Orthop 2016;10(1):15-18. DOI: 10.1007/s11832-0160712-1.

33. Dobbs MB, Gerlach D, Limpaphyayom N, Use of the Ponseti method for the treatment of clubfoot associated with myelodysplasia. Pediatric Orthopaedic Society Annual Meeting; May 23-26, 2007; Hollywood, Florida.

34. Gerlach DJ, Gurnett CA, Limpaphayom N, et al. Early results of the Ponseti method for the treatment of clubfoot associated with myelomeningocele. J Bone Joint Surg [Am] 2009;91-A(6):1350-1359. DOI: 10.2106/JBJS.H.00837.

35. Kowalczyk B, Felus J. Ponseti casting and Achilles release versus classic casting and soft tissue releases for the initial treatment of arthrogrypotic clubfeet. Foot Ankle Int 2015;36(9):1072-1077. DOI: 10.1177/1071100715581656.

36. Dunkley M, Gelfer Y, Jackson D, et al. Mid-term results of a physiotherapist-led Ponseti service for the management of nonidiopathic and idiopathic clubfoot. J Child Orthop 2015;9(3):183-189. DOI: 10.1007/s11832-015-0658-8.

37. Segev E, Ezra E, Yaniv M, et al. V osteotomy and llizarov technique for residual idiopathic or neurogenic clubfeet. J Orthop Surg (Hong Kong) 2008;16(2):215-219. DOI: 10.1177/230949900801600218.

38. Eidelman M, Katzman A. Treatment of arthrogrypotic foot deformities with the Taylor spatial frame. J Pediatr Orthop 2011;31(4):429-434. DOI: 10.1097/BPO.0b013e3182172392. 